\title{
ENERGY CONSUMPTION AND CARBON DIOXIDE EMISSION CONSIDERATIONS IN THE URBAN PLANNING PROCESS IN MALAYSIA
}

\author{
Wee-Kean Fong' \\ CTI ENGINEERING INTERNATIONAL CO., LTD., JAPAN \\ Hiroshi Matsumoto \\ TOYOHASHI UNIVERSITY OF TECHNOLOGY, JAPAN \\ Chin-Siong $\mathbf{H o}^{2}$ \\ UNIVERSITI TEKNOLOGI MALAYSIA, MALAYSIA \\ Yu-Fat Lun \\ TOHOKU UNIVERSITY, JAPAN
}

\begin{abstract}
In handling global warming issues, among the most important measures are to reduce energy consumptions and carbon dioxide emissions. While many countries have recognized the importance of the role of urban planning in energy conservation and reduction of carbon dioxide emissions, spatial planning framework in Malaysia is still lacking in this aspect. Although there are some spatial planning policies indirectly favoring energy conservation, there is still no measure that directly emphasizes on promoting energy conservation and capping carbon dioxide emissions. Energy and carbon dioxide issues should thus be taken as one of the core parts in the urban planning process. It is necessary to develop and incorporate a decision making tool to assess the overall impact of development plans on energy consumptions and carbon dioxide emissions. While achieving the desired economic and social developments, it is necessary to create a low energy-consuming, carbon dioxide-emitting sustainable society.
\end{abstract}

Keywords: Global warming, Energy consumption, Carbon dioxide emission, Urban planning

\footnotetext{
1 He can be contacted at fong@ctii.co.jp or fwkeanjp@yahoo.co.jp.

${ }^{2}$ He can be contacted at csho59@yahoo.com.
} 


\section{INTRODUCTION}

The world is facing the challenges of global warming and climate change issues. The anthropogenic driver of climate change is the increasing concentration of greenhouse gases (GHG) in the atmosphere. Carbon dioxide $\left(\mathrm{CO}_{2}\right)$ is the most important anthropogenic greenhouse gas, and the global increase in carbon dioxide concentration is due primarily to fossil fuel use and land use change (IPCC, 2007).

The most significant increase of energy consumptions and $\mathrm{CO}_{2}$ emissions is taking place in cities, where rapidly expanding populations enjoy higher living standards and material affluence (Fong et al., 2007a \& 2007b; IGES, 2004). Thus, dealing with the issues of energy consumptions and $\mathrm{CO}_{2}$ emissions, it is necessary to focus on the urban sector, and urban planning plays an important role in combating global warming, or at a small scale, mitigating the urban heat island (UHI) phenomenon.

One of the key principles in urban planning is to achieve 'sustainable development'. The most well-known definition of sustainable development that is accepted by the United Nations is 'development that meets the needs of the present without compromising the ability of future generations to meet their own needs'. In achieving sustainable development, there are many aspects that should be taken into consideration. The Division for Sustainable Development under the UN Department of Economic and Social Affairs has listed down the fields within the scope of sustainable development, and 'climate change' and 'energy' are among the main focuses (UN, 2007). Hence, it is necessary to take the climate change and energy issues as one of the main considerations in the urban planning process. However, studies show that population and economic growth are the major driving forces behind increasing energy consumption and $\mathrm{CO}_{2}$ emissions (Fong et al., 2007a; IGES, 2004). So, it would be a big challenge to maintain the high quality of life in the cities while ensuring low energy consumptions and $\mathrm{CO}_{2}$ emissions.

In recent years, due to the increasing concerns on global warming issues that are closely associated with $\mathrm{CO}_{2}$ emissions, the concept of 'low carbon city' is currently gaining popularity among the urban planners and city governments. Planning of low carbon cities involves creation of a low carbon society (LCS) by promoting low carbon emissions. The increases of $\mathrm{CO}_{2}$ concentration are due primarily to fossil fuel use and land use change. Hence, urban planning, through land use planning and planning control can play a vital role in implementing the idea of low carbon city, particularly during the formulation of development plans (Ho and Fong, 2007). 
This paper attempts to highlight the importance of energy conservation and reduction of $\mathrm{CO}_{2}$ emissions, and to examine the spatial planning process in Malaysia from the perspective of energy consumptions and $\mathrm{CO}_{2}$ emissions. It provides a guide for further consideration in incorporating energy and $\mathrm{CO}_{2}$ issues as the core part of urban planning process, in achieving sustainable development based on the concept of low carbon city.

\section{GLOBAL WARMING, CARBON DIOXIDE EMISSIONS AND ENERGY CONSUMPTIONS}

\section{Global Warming and Climate Change}

The issues of global warming and climate change have become a subject of intense interest all over the world since the last decade. Warming of the climate system is now evidenced from observations of increases in global average air and ocean temperatures, widespread melting of snow and ice, and rising global average sea level.

In the Climate Change 2007 report (IPCC, 2007), the Intergovernmental Panel on Climate Change (IPCC) reported that eleven of the last twelve years (19952006) rank among the 12 warmest years in the instrumental record of global surface temperature since 1850 , and the total temperature increase from 1850 1899 to $2001-2005$ is about $0.76^{\circ} \mathrm{C}$. It is predicted a rise in the average global surface temperature of about $2^{\circ} \mathrm{C}$ between 1990 and 2100 (IPCC, 2004).

The same report also revealed that, as a result of global warming, mountain glaciers and snow cover have declined and contributed to sea level rise. Global average sea level rose at an average rate of $1.8 \mathrm{~mm}$ per year over the period of 1961 to 2003 . The rate was faster over 1993 to 2003 , which was about $3.1 \mathrm{~mm}$ per year.

Also, at continental, regional, and ocean basin scales, numerous long-term changes in climate have been observed. These include changes in Arctic temperatures and ice, widespread changes in precipitation amounts, ocean salinity, wind patterns and aspects of extreme weather including droughts, heavy precipitation, heat waves and the intensity of tropical cyclones. Average Arctic temperatures increased at almost twice of the global average rate in the past 100 years. Satellite data since 1978 showed that annual average Arctic sea ice extent has shrunk by $2.7 \%$ per decade, with larger decreases in summer i.e. $7.4 \%$ per decade. 
In term of precipitation, long-term observation from 1900 to 2005 showed significant increase in precipitation in eastern parts of North and South America, northern Europe and northern and central Asia, while drying has been observed in the Sahel, the Mediterranean, southern Africa and parts of southern Asia. More intense and longer droughts have been observed over wider areas since the 1970s, particularly in the tropics and subtropics. Increased drying linked with higher temperatures and decreased precipitation has contributed to changes in drought.

It was also reported that increase of intense tropical cyclone activity in the North Atlantic since 1970 is correlated with increasing tropical sea surface temperatures.

\section{Global Warming and Carbon Dioxide Emissions}

Human activities influence the environment. Human activities, in particular those involving the combustion of fossil fuels and biomass burning, produce GHG that affects the composition of the atmosphere and lead to the depletion of the stratospheric ozone layer. Land use change due to urbanization and forestry and agricultural activities is also affecting the physical and biological properties of the earth surface and subsequently affecting the regional and global climate (IPCC, 2001).

The increase in GHG concentrations in the atmosphere affects processes and feedbacks in the climate system. Qualitatively, an increase of atmospheric GHG concentrations will lead to an average increase of the temperature of the surface-troposphere system. In this respect, $\mathrm{CO}_{2}$ is the most important anthropogenic GHG. Increased $\mathrm{CO}_{2}$ emissions from fossil fuel use is certain to be the dominant influence on the trends in atmospheric $\mathrm{CO}_{2}$ concentration that eventually resulted in rising global temperatures and sea level (IPCC, 2005).

$\mathrm{CO}_{2}$ is the GHG that has the largest contribution from human activities (IPCC, 2005). The global atmospheric concentration of $\mathrm{CO}_{2}$ has increased from a preindustrial value of about $280 \mathrm{ppm}$ to $379 \mathrm{ppm}$ in 2005 . The atmospheric concentration of $\mathrm{CO}_{2}$ in 2005 exceeds by far the natural range over the last 650,000 years (180 to $300 \mathrm{ppm}$ ) as determined from ice cores. The annual $\mathrm{CO}_{2}$ concentration growth rate was larger during the last 10 years (1995-2005 average: $1.9 \mathrm{ppm}$ per year), than it has been since the beginning of continuous direct atmospheric measurements (1960-2005 average: 1.4 ppm per year) although there is year-to-year variability in growth rates. (IPCC, 2007) 


\section{Carbon Dioxide Emissions and Energy Use}

$\mathrm{CO}_{2}$ is the most abundant anthropogenic (human-caused) GHG in the atmosphere. Emissions of $\mathrm{CO}_{2}$ arise from a number of sources, mainly fossil fuel combustion in the power generation, industrial, residential and transportation sectors. It is released into the atmosphere by the combustion of fossil fuels such as coal, oil or natural gas, and renewable fuels like biomass (IPCC, 2005).

According to the International Energy Outlook 2006 (cf. Figure 1), world $\mathrm{CO}_{2}$ emissions from the consumption of fossil fuels is expected to grow at an average rate of $2.1 \%$ per year from 2003 to 2030 . The world $\mathrm{CO}_{2}$ emission from the consumption of fossil fuels is predicted to increase from about 25,000 billion metric tons in 2003, to more than 40,000 billion metric tons by 2030 .

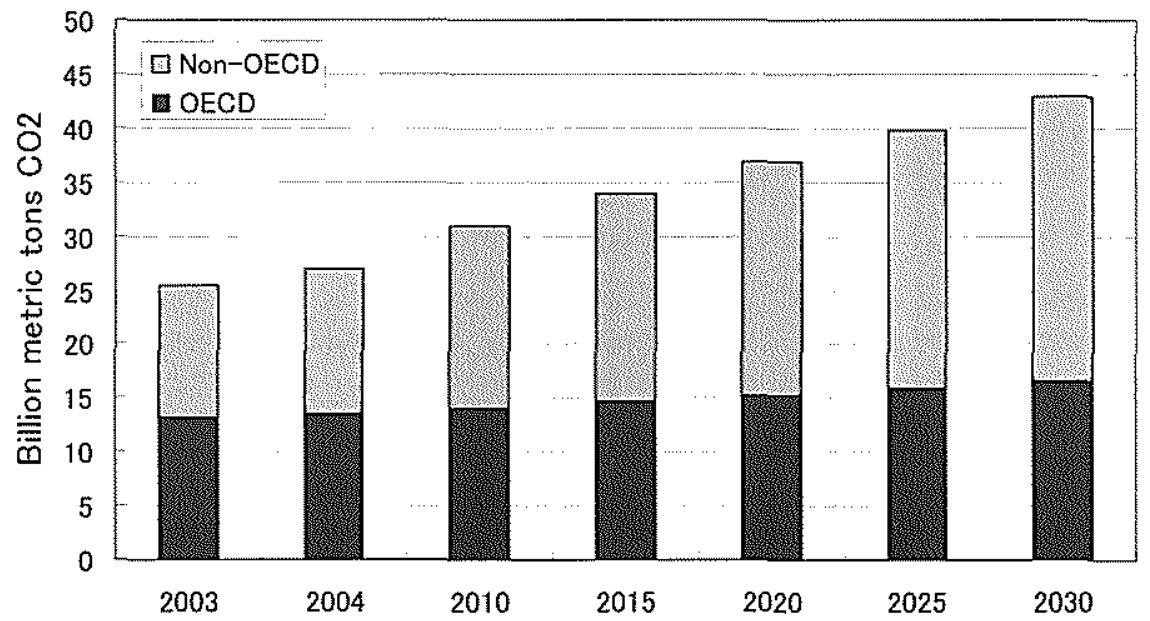

Figure 1: World energy-related $\mathrm{CO}_{2}$ emissions by region, 1990-2030 (EIA, 2007)

The relative contributions of different fossil fuels to total energy-related $\mathrm{CO}_{2}$ emissions have changed over time as shown in Figure 2. Increasing trend of $\mathrm{CO}_{2}$ emissions is observed for all fuel types and they are projected to further increase steadily over the projection period up to 2030. However, emissions from petroleum and other liquids that made up the largest proportion $(42 \%)$ of world total emissions in 1990, was overtaken by coal since 2005. By 2030, it is projected that coal and liquids (petroleum and other liquids) will each be 
contributing $43 \%$ and $36 \%$ of the world total emissions. The increasing share of coal is reflective of its important role in the energy mix of non-OECD countries, especially China and India (EIA, 2007). In 1990, emissions from China and India combined constituted $13 \%$ of world emissions, but by 2004 , that share rose to $22 \%$, largely because of a strong increase in coal use in these two countries. This trend is projected to continue, and by $2030 \mathrm{CO}_{2}$ emissions from China and India combined are projected to account for $31 \%$ of total world emissions, with China alone responsible for $26 \%$ of the world total.

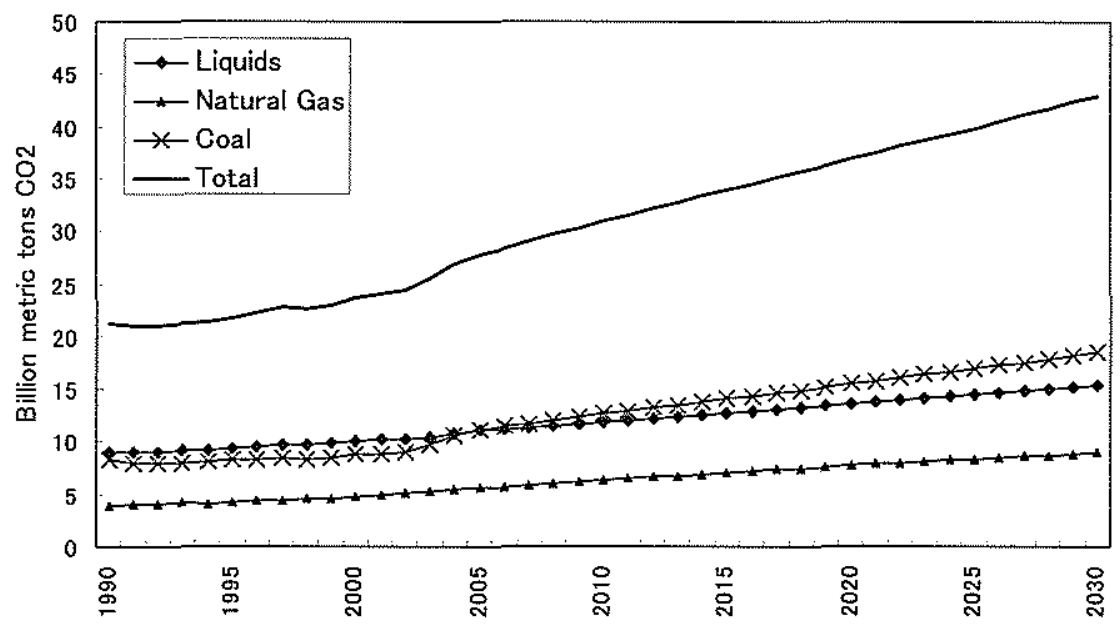

Figure 2: World energy-related $\mathrm{CO}_{2}$ emissions by fuel type, 1990-2030 (EIA, 2007)

\section{GLOBAL AND MALAYSIAN CARBON DIOXIDE EMSSION AND ENERGY CONSUMPTION TRENDS}

\section{Carbon Dioxide Emissions}

Figure 1 above reveals that world $\mathrm{CO}_{2}$ emissions is at an increasing trend. Every country contributes different amounts of $\mathrm{CO}_{2}$ into the atmosphere. From the figure, it can be seen that the growth rate of $\mathrm{CO}_{2}$ emissions from non-OECD countries is higher than the OECD countries. 2004 marked the first time in history that energy-related $\mathrm{CO}_{2}$ emissions from the non-OECD countries exceeded those from the OECD countries. Furthermore, because the projected average annual increase in emissions from 2004 to 2030 in the non-OECD countries $(2.6 \%)$ is more than three times the increase projected for the OECD countries $(0.8 \%), \mathrm{CO}_{2}$ emissions from the non-OECD countries in 2030 , at 26.2 
billion metric tons, are projected to exceed those from the OECD countries by $57 \%$.

Table 1 shows the regional shares of $\mathrm{CO}_{2}$ emissions against the world total emissions. In line with Figure 1, the share of OECD countries dropped from $65.9 \%$ in 1973 to $47.6 \%$ in 2005 . Increases of share are seen in most of the other regions, including Asia, Latin America, Africa and Middle East. Among these regions, Asia has the most significant increase. Including China, the share of $\mathrm{CO}_{2}$ emissions from Asia escalated from $8.7 \%$ in 1973 to $28.3 \%$ in 2005 . The rapid increase of $\mathrm{CO}_{2}$ emissions from these non-OECD developing countries are mainly due to the development and industrialization over the last decades. Comparing this with the data shown in Figure 2, it can be seen that the rapid increase of $\mathrm{CO}_{2}$ emissions from non-OECD developing countries is very closely related to the increased usage of coal as an energy source. Coal is not only the most carbon-intensive fossil fuels, but is also the fastest growing energy source. The increasing share of coal is reflective of its important role in the energy mix of non-OECD countries, especially China and India. In 1990, China and India combined for $13 \%$ of world emissions, but by 2004 that share had risen to $22 \%$, which is largely because of a strong increase in coal use in these two countries (EIA, 2007).

Table 1: Regional shares of $\mathrm{CO}_{2}$ emission, 1973 and 2005

\begin{tabular}{|l|l|l|}
\hline Region/Country & Shares against world total $\mathrm{CO}_{2}$ emissions \\
\hline & 1973 & 2005 \\
\hline OECD & $65.9 \%$ & $47.6 \%$ \\
\hline Non-OECD Europe & $1.7 \%$ & $1.0 \%$ \\
\hline Former USSR & $14.4 \%$ & $8.5 \%$ \\
\hline Asia (excluding China) & $3.0 \%$ & $9.5 \%$ \\
\hline Latin America & $2.7 \%$ & $3.5 \%$ \\
\hline Africa & $1.9 \%$ & $3.1 \%$ \\
\hline Middle East & $1.0 \%$ & $4.6 \%$ \\
\hline China & $5.7 \%$ & $18.8 \%$ \\
\hline Bunkers & $3.7 \%$ & $3.4 \%$ \\
\hline World total, mil metric tons & 15,661 & 27.136 \\
\hline
\end{tabular}
Notes:

1. World includes international aviation and international marine bunkers, which are shown together as Bunkers.

2. $\mathrm{CO}_{2}$ emissions are from fuel combustion only.

Source: IEA, 2007.

Table 1 reveals that increase of $\mathrm{CO}_{2}$ emissions in Asia is very significant over the past decades due to rapid economic growth and industrialization. Malaysia, 
as part of Asia, is also experiencing rapid economic and population growth, and is expected to achieve the status of a developed nation by 2020 as envisaged under the Vision 2020 (EPU, 2001). The gross domestic product (GDP) growth of Malaysia was $7.0 \%$ during the last decade of the past century (1990-2000), and despite the Asian economic downturn in the late 1990's, the GDP growth rate was still maintained at $4.5 \%$ over the period of 2001-2005 (EPU, $2001 \&$ 2006). In terms of population, Malaysian population has grown from 10.3 millions in 1970 to 27.6 millions in 2007 , more than $260 \%$ growth over the 37 year period.

Table 2: $\mathrm{CO}_{2}$ emissions of the world and the selected regions \& countries, 2005

\begin{tabular}{|c|c|c|c|c|c|}
\hline Region/country & $\begin{array}{l}\text { Population, } \\
\text { million }\end{array}$ & $\begin{array}{l}\text { GDP, } \\
\text { billion } \\
2000 \mathrm{~S}\end{array}$ & $\begin{array}{l}\mathrm{CO}_{2} \\
\text { emissions, } \\
\text { million } \\
\text { metric tons }\end{array}$ & $\begin{array}{l}\mathrm{CO}_{2} / \mathrm{capita} \\
\text { metric ton }\end{array}$ & $\begin{array}{l}\mathrm{CO}_{2} / \mathrm{GDP} \\
\mathrm{kgCO}_{2} / \\
2000 \mathrm{~S}\end{array}$ \\
\hline World & 6,432 & 36,281 & 27,136 & 4.22 & 0.75 \\
\hline \multicolumn{6}{|l|}{ World regions: } \\
\hline OECD & 1,172 & 28,394 & 12,910 & 11.02 & 0.45 \\
\hline Non-OECD Europe & 54 & 152 & 263 & 4.87 & 1.73 \\
\hline Former USSR & 285 & 525 & 2,303 & 8.08 & 4.39 \\
\hline Asia (excl. China) & 2,080 & 1,974 & 2,591 & 1.25 & 1.31 \\
\hline Latin America & 449 & 1,620 & 938 & 2.09 & 0.58 \\
\hline Africa & 894 & 731 & 835 & 0.93 & 1.14 \\
\hline Middle East & 187 & 786 & 1,238 & 6.62 & 1.58 \\
\hline China & 1,311 & 2,098 & 5,101 & 3.89 & 2.43 \\
\hline \multicolumn{6}{|l|}{ G8 countries: } \\
\hline Canada & 32.27 & 822.39 & 548.59 & 17.00 & 0.67 \\
\hline France & 62.70 & $1,430.13$ & 388.38 & 6.19 & 0.27 \\
\hline Germany & 82.46 & $1,961.79$ & 813.48 & 9.87 & 0.41 \\
\hline Italy & 58.53 & $1,132.83$ & 454.00 & 7.76 & 0.40 \\
\hline Japan & 127.76 & $4,994.13$ & $1,214.19$ & 9.50 & 0.24 \\
\hline Russia & 143.11 & 349.85 & $1,543.76$ & 10.79 & 4.41 \\
\hline United Kingdom & 60.22 & $1,626.78$ & 529.89 & 8.80 & 0.33 \\
\hline United States & 296.68 & $10,995.80$ & $5,816.96$ & 19.61 & 0.53 \\
\hline \multicolumn{6}{|l|}{ Southeast Asia: } \\
\hline Brunei & 0.37 & 4.85 & 5.09 & 13.76 & 1.05 \\
\hline Cambodia & 13.64 & 5.66 & 3.71 & 0.27 & 0.66 \\
\hline Indonesia & 220.56 & 207.74 & 340.98 & 1.55 & 1.64 \\
\hline Malaysia & 25.35 & 112.46 & 138.04 & 5.45 & 1.23 \\
\hline Myanmar & 50.52 & 15.20 & 11.02 & 0.22 & 0.73 \\
\hline Philippines & 83.05 & 93.73 & 76.42 & 0.92 & 0.82 \\
\hline Singapore & 4.34 & 112.22 & 43.10 & 9.93 & 0.38 \\
\hline Thailand & 64.23 & 157.07 & 214.29 & 3.34 & 1.36 \\
\hline Vietnam & 83.12 & 44.75 & 80.36 & 0.97 & 1.80 \\
\hline
\end{tabular}

Source: IEA, 2007 
Table 2 presents the population, GDP and $\mathrm{CO}_{2}$ emissions of Malaysia in comparison with the world, selected regions, and countries. Due to rapid economic growth and industrialization, $\mathrm{CO}_{2}$ emission of Malaysia is relatively high compared to the world average and other Southeast Asian countries. In terms of per capita emission, Malaysia marks 5.45 metric tons, much higher than the world and Asian (excluding China) average figures of 4.22 metric tons and 1.25 metric tons respectively. Although this value is lower than developed countries, it ranks third in Southeast Asia, after Brunei and Singapore.

In terms of total $\mathrm{CO}_{2}$ emission, the figure for Malaysia is also quite high compared to the other developing Southeast Asian countries, which is the third highest after Indonesia and Thailand. Although the total emission for Malaysia is only about $40 \%$ of Indonesia and $64 \%$ of Thailand, the per capita emission of Malaysia is about 3.5 and 1.6 times of the values of Indonesia and Thailand respectively.

For the intensity of $\mathrm{CO}_{2}$ emission $\left(\mathrm{CO}_{2} / \mathrm{GDP}\right)$, although the figure for Malaysia $\left(1.23 \mathrm{kgCO}_{2} / 2000 \$\right)$ is quite high compared to the world average $(0.75$ $\left.\mathrm{kgCO}_{2} / 2000 \$\right)$ and most of the developed countries (0.24-0.67 $\left.\mathrm{kgCO}_{2} / 2000 \$\right)$, it is similar to the Asian average (excluding China) and much lower than Vietnam, Indonesia and Thailand in Southeast Asia. In this respect, it can be seen that emission intensities of the developing countries are generally higher than the developed countries. Besides the factor of energy efficiency, as mentioned above, it could also be attributed to the more intensive usage of coal as an energy source.

One important issue regarding the database for $\mathrm{CO}_{2}$ emissions in Malaysia is the inconsistency of data. For example, as shown in the above Table 2, the International Energy Agency reported that $\mathrm{CO}_{2}$ emissions in Malaysia in 2005 was 5.45 metric tons per capita, whereas the United Nations revealed a value of 6.2 metric tons per capita for year 2002, and on the other hand, the World Resources Institute published a value of 5.4 metric tons per capita for year 2000 (IEA, 2007; UNEP, 2007; WRI, 2007). The questions are not only the consistency of the volume of emissions but also the base year of this data.

For the database on $\mathrm{CO}_{2}$ emissions in Malaysia, the most reliable data is deemed to be the inventory developed by the Malaysia National Steering Committee on Climate Change, which was established subsequent to the signing of the Kyoto Protocol. The national GHG inventory was established during the preparation of the Initial National Communication (INC) for the UNFCCC, which was based on the 1994 database. After the Cabinet of 
Malaysia had reviewed and approved the draft, the NC was launched on 18 July 2000 and submitted to the UNFCCC Secretariat on 22 August 2000 (MOSTE, 2000). Table 3 shows the emissions of the three main GHGs in 1994 on a sectoral basis. In order to provide an overall assessment, the various GHG emissions are also expressed as the equivalent of $\mathrm{CO}_{2}$ emissions.

Table 3: Summary of Malaysia national GHG emissions and removal, 1994

\begin{tabular}{|c|c|c|c|c|c|c|c|}
\hline \multirow[t]{2}{*}{ Categories } & \multicolumn{2}{|c|}{$\mathrm{CO}_{2}$} & \multicolumn{2}{|c|}{ CG4 } & \multicolumn{2}{|c|}{$\mathrm{N} 2 \mathrm{O}$} & \multirow{2}{*}{$\begin{array}{ll} & \mathrm{CO}_{2} \\
\text { equivalent } & (\mathrm{Gg})\end{array}$} \\
\hline & Gg & $\%$ & $\mathrm{Gg}$ & $\%$ & $\mathrm{Gg}$ & $\%$ & \\
\hline Energy & 84,415 & 86.7 & 635 & 28.5 & 0.350 & 86.4 & 97,852 \\
\hline Industrial process & 4,973 & 5.1 & - & - & - & - & 4,973 \\
\hline Agriculture & - & - & 329 & 14.8 & 0.0054 & 13.3 & 6,925 \\
\hline Waste & 318 & 0.3 & 1,267 & 56.8 & - & $=$ & 26,925 \\
\hline Land use change & 7,636 & 7.8 & 0.13 & 0.006 & 0.001 & 0.3 & 7,639 \\
\hline Total (emission) & 97,342 & 100.0 & 2,231 & 100.0 & 0.405 & 100.0 & 144,314 \\
\hline $\begin{array}{l}\text { Net total (after } \\
\text { subtracting sink) }\end{array}$ & 28,625 & - & - & - & - & - & 75,597 \\
\hline
\end{tabular}

Note: Total $\mathrm{CO}_{2}$ emission from international bunker is $785.55 \mathrm{Gg}$, which has already been subtracted from the total $\mathrm{CO}_{2}$ emissions in energy sector:

Source: MOSTE, 2000

Table 4 (INC column) shows the $\mathrm{CO}_{2}$ emissions from final energy use (excluding electricity) by economy sector: transportation $(49 \%)$, industries (41\%), residential and commercial activities (7\%), and agriculture (3\%). It is noted that the final $\mathrm{CO}_{2}$ emission totaling $43,768 \mathrm{Gg}$ from final energy use (excluding electricity) as shown in Table 4 is very much less than the emission of $84,415 \mathrm{Gg}$ estimated from primary energy supply as shown in Table 3 . The latter assumed that all types of fuel are consumed for energy transformation and final use. The difference between the primary energy supply and energy demand (final use) figures could be attributed to, among others, transformation to secondary supply of energy, losses incurred during transformation and transmission, and statistical discrepancies. (MOSTE, 2000)

Subsequent to the NC that was based on the database of 1994, as an update of the first NC, the preparation of the Second NC (NC2) with the base year of 2000 was commissioned recently and scheduled to be launched in 2009. Table 4 presents the preliminary results on the $\mathrm{CO}_{2}$ emissions from energy use in comparison with the $\mathrm{INC}$ data. The breakdown of $\mathrm{CO}_{2}$ emissions by sector shows that it is dominated by transportation (31\%), energy industries $(28 \%)$ (within the category of 'energy industries and others'), and manufacturing industries (22\%). Comparing the data between 1994 and 2000 (excluding energy industries) revealed a significant increase of $53 \%$ in $\mathrm{CO}_{2}$ emissions from 
energy use. Within these six years, $\mathrm{CO}_{2}$ emissions had increased from 43,768 $\mathrm{Gg}$ to $93,621 \mathrm{Gg}$. However, it must be noted that the sectoral energy use under the 1996 IPCC Guidelines have been refined, hence a direct comparison between these two years is rather complicated.

Table 4: $\mathrm{CO}_{2}$ emissions from fuel combustion in Malaysia based on total final use, 1994

\begin{tabular}{|c|c|c|c|c|c|}
\hline Source of data & \multicolumn{2}{|l|}{$\mathrm{INC}$} & \multicolumn{2}{|l|}{$\mathrm{NC2}$} & \multirow{3}{*}{ Increase } \\
\hline Year & \multicolumn{2}{|l|}{1994} & \multicolumn{2}{|l|}{2000} & \\
\hline Sectors & $\begin{array}{l}\mathrm{CO}_{2} \text { emissions } \\
(\mathrm{Gg})\end{array}$ & Shares & $\begin{array}{l}\mathrm{CO}_{2} \text { emissions } \\
(\mathrm{Gg})\end{array}$ & Shares & \\
\hline $\begin{array}{l}\text { Residential } \& \\
\text { commercial }\end{array}$ & 3,014 & $7 \%$ & 3,947 & $3 \%$ & $\begin{array}{l}933 \\
(24 \%) \\
\end{array}$ \\
\hline Industrial & 18,083 & $41 \%$ & 28,855 & $22 \%$ & $\begin{array}{l}10,772 \\
(37 \%)\end{array}$ \\
\hline Transportation & 21,375 & $49 \%$ & 41,008 & $31 \%$ & $\begin{array}{l}19,633 \\
(48 \%) \\
\end{array}$ \\
\hline Agriculture & 1,296 & $3 \%$ & 917 & $1 \%$ & $\begin{array}{l}-379 \\
(-41 \%)\end{array}$ \\
\hline $\begin{array}{l}\text { Energy industries } \\
\text { and others }\end{array}$ & $\mathrm{n} / \mathrm{a}$ & - & 56,019 & $43 \%$ & - \\
\hline Total & 43,768 & $100 \%$ & 130,746 & $100 \%$ & - \\
\hline
\end{tabular}

nfa: not available. Note: In the INC, energy industries was excluded from the $\mathrm{CO}_{2}$ emission calculation.

Source: INC: MOSTE, 2000; NC2: Azman ef al., 2006

From the above, it can be seen that the national data on $\mathrm{CO}_{2}$ emissions is rather complete although there are some variations between different sources of data. However, literature review revealed that there is complete absence of local level $\mathrm{CO}_{2}$ emission data in Malaysia. In view of the fact that the main source of $\mathrm{CO}_{2}$ emissions is from the urban sector (to be explained in further detail in the later sections), there is an urgent need to establish the local level (city level) $\mathrm{CO}_{2}$ emission data in Malaysia, especially for the major cities such as Kuala Lumpur (or Klang Valley) and Johor Bahru (or the Iskandar Development Region).

\section{Energy Consumptions}

Despite high oil prices, the world economic growth is expected to continue with strong growth, driving the robust increase in world energy use. The total world consumption of marketed energy is expected to increase from about 421 quadrillion British thermal units (Btu) in 2003 to 722 quadrillion Btu in 2030 ( $71 \%$ increase) (cf. Table 4$)$. 
When comparing the energy consumption of developed and developing countries, from Table 4, it can be seen that the growth rate in energy consumption for the non-OECD countries, including Malaysia, accounts for three-fourths of the increase in world energy use. Non-OECD energy use is expected to surpass OECD energy use by year 2015. In 2030, total energy demand in non-OECD countries will exceed that in the OECD countries by $34 \%$. During this projection period, the average growth rate of energy consumption in the non-OECD countries is triple of the OECD countries.

Table 4: World marketed energy consumption by country grouping, 2003-2030

\begin{tabular}{|c|c|c|c|c|c|c|c|}
\hline \multirow[b]{2}{*}{ Region } & \multicolumn{6}{|c|}{ Energy consumption, quadrillion Btu } & \multirow[b]{2}{*}{$\%$ p.a } \\
\hline & 2003 & 2010 & 2015 & 2020 & 2025 & 2030 & \\
\hline OECD & 234.3 & 256.1 & 269.9 & 281.6 & 294.5 & 308.8 & 1.0 \\
\hline North America & 118.3 & 131.4 & 139.9 & 148.4 & 157.0 & 166.2 & 1.3 \\
\hline Europe & 78.9 & 84.4 & 87.2 & 88.7 & 91.3 & 94.5 & 0.7 \\
\hline Asia & 37.1 & 40.3 & 42.8 & 44.4 & 46.1 & 48.0 & 1.0 \\
\hline Non-OECD & 186.4 & 253.6 & 293.5 & 331.5 & 371.0 & 412.8 & 3.0 \\
\hline Europe \& Eurasia & 48.5 & 56.5 & 62.8 & 68.7 & 74.0 & 79.0 & 1.8 \\
\hline Asia & 83.1 & 126.2 & 149.4 & 172.8 & 197.1 & 223.6 & 3.7 \\
\hline Middle East & 19.6 & 25.0 & 28.2 & 31.2 & 34.3 & 37.7 & 2.4 \\
\hline Africa & 13.3 & 17.7 & 20.5 & 22.3 & 24.3 & 26.8 & 2.6 \\
\hline Central \& South America & 21.9 & 28.2 & 32.5 & 36.5 & 41.2 & 45.7 & 2.8 \\
\hline Total WorId & 420.7 & 509.7 & 563.4 & 613.0 & 665.4 & 721.6 & 2.0 \\
\hline
\end{tabular}

Note: Totals may not equal sum of components due to independent rounding

Source: IEA, 2007

When comparing among different regions of non-OECD countries, from the same table, it is obvious that Asia constitutes the largest portion, about $54 \%$ of the energy consumption. Also, in terms of growth rate, it is $3.7 \%$ p.a., the highest among all the regions.

From the above Table 4, it was found that developing countries are consuming more energy, while among the developing countries, Asia as a region consumes the most. Table 5 presents the comparison of energy consumption patterns for G8 developed countries and Southeast Asian developing countries. In term of per capita energy consumption, the values of developed countries are very much higher than the developing countries. While among the developing countries, the per capita energy consumption of Malaysia is 106.3 million Btu, which is comparatively high compared to the other Southeast Asian countries (except Brunei and Singapore) that generally are lower than 60 million Btu.

In terms of energy intensity, comparatively, the energy intensities of the developed countries are also generally higher than the developing countries, 
particularly for the case of Canada and Russia. Similarly, among the developing countries, it can be seen that the energy intensity of Malaysia is obviously higher than other developing countries, and in fact it is higher than quite a number of developed countries.

Table 5: Comparison of energy consumption pattern in selected countries, 2005

\begin{tabular}{|l|l|l|}
\hline \multirow{2}{*}{ Country } & Primary energy consumption \\
\cline { 2 - 3 } & $\begin{array}{l}\text { Per capita } \\
\text { (million Btu) }\end{array}$ & $\begin{array}{l}\text { Energy intensity } \\
\text { (Btu per 2000 US } \$ \text { ) }\end{array}$ \\
\hline G8 countries & & \\
\hline Canada & 436.2 & 13,825 \\
\hline France & 181.5 & 7,243 \\
\hline Germany & 176.0 & 7,021 \\
\hline Italy & 138.9 & 5,788 \\
\hline Japan & 177.0 & 6,539 \\
\hline Russia & 212.2 & 14,935 \\
\hline United Kingdom & 165.7 & 6,048 \\
\hline United States & 340.5 & 9,113 \\
\hline Southeast Asian countries & & \\
\hline Brunei & 314.4 & 17,952 \\
\hline Cambodia & 0.6 & 302 \\
\hline Indonesia & 23.4 & 5,839 \\
\hline Malaysia & 106.3 & 9,253 \\
\hline Myanmar & 5.4 & 1764 \\
\hline Philippines & 15.2 & 4,865 \\
\hline Singapore & 457.1 & 15,444 \\
\hline Thailand & 56.5 & 6,848 \\
\hline Vietnam & 14.7 & 4,857 \\
\hline
\end{tabular}

Source: $E I A, 2007$

Table 6 shows the final commercial energy consumption in Malaysia during the Eighth and Ninth Malaysia Plans period, which covers the period of 2000 to 2010. In this respect, it includes the total energy delivered to final consumers, but excluding gas, coal and fuel oil used in electricity generation. The data show that the energy consumption has grown from 1,244 PJ in 2000 to 1,632 PJ in 2005 , and expected to further grow up to $2,218 \mathrm{PJ}$ by 2010 . In line with the rapid economic and population growths, the energy consumption growth rate for $2000-2005$ was $5.6 \%$ p.a., and it is projected to increase up to $6.3 \%$ p.a. in 2005-2010.

In terms of sectoral demand, no major change is expected during the period of 2000 to 2010 , in which transport and industrial each constitutes about two fifths 
of the total consumption, and followed by residential/commercial, non-energy and agriculture/forestry.

Table 6: Final commercial energy demand by sector, Malaysia

\begin{tabular}{|l|l|l|l|l|l|}
\hline Sources & \multicolumn{3}{|l|}{ Energy consumption( (PJ) } & \multicolumn{3}{l|}{ Growth rate (\% pa) } \\
\cline { 2 - 7 } & $2000(\%)$ & $2005(\%)$ & $2010 \%)$ & $2000-2005$ & $2005-2010$ \\
\hline Industrial & 477.6 & 630.7 & 859.9 & 5.7 & 6.4 \\
& $(38.4 \%)$ & $(38.6 \%)$ & $(38.8 \%)$ & & \\
\hline Transport & 505.5 & 661.3 & 911.7 & 5.5 & 6.6 \\
& $(40.6 \%)$ & $(40.5 \%)$ & $(41.1 \%)$ & & \\
\hline Resident/ & 162.0 & 213 & 284.9 & 5.6 & 6.0 \\
commercial & $(13.0 \%)$ & $(13.1 \%)$ & $(12.8 \%)$ & & \\
\hline Non energy & 94.2 & 118.7 & 144.7 & 4.7 & 4.0 \\
& $(7.6 \%)$ & $(7.3 \%)$ & $(6.5 \%)$ & & \\
\hline $\begin{array}{l}\text { Agriculture/ } \\
\text { Forestry }\end{array}$ & 4.4 & 8.0 & 16.7 & 12.9 & 15.9 \\
\hline Total & $(0.4 \%)$ & $(0.5 \%)$ & $0.8 \%)$ & & \\
\hline
\end{tabular}

Note :

'Include manufacturing, mining and construction.

${ }^{2}$ Include natural gas, bitumen, asphalt, industrial feedstock and grease.

Source: EPU, 2006.

With respect to per capita consumption, in terms of final commercial energy demand, it was 52.9 GJ in 2000 , and then rapidly increased to $62.2 \mathrm{GJ}$ in 2005 . In line with the projected strong national economic growth, it is projected to further escalate to $76.5 \mathrm{GJ}$ by 2010 , more than $40 \%$ increase over the 10 -year period from 2000 to 2010 (EPU, 2006).

\section{INTERNATIONAL COOPERATION IN HANDLING GLOBAL WARMING ISSUES}

Global warming and climate change are the two greatest issues to mankind currently. The urgency to fight against them has drawn serious attentions from leaders, scientists and individuals all over the world. In fact, the event that for the first time drawing attentions from the world on the global warming and climate change issues can be traced back to the first "World Climate Conference" organized by the World Meteorological Organization (WMO) in 1979. The conference expressed concern that "continued expansion of man's activities on earth may cause significant extended regional and even global changes of climate", and it called for "global cooperation to explore the possible future course of global climate and to take this new understanding into account in planning for the future development of human society" (IPCC, 2004). 
Subsequent to the said conference, various international efforts have been taken to monitor the climate change and to mitigate it. In 1988, the IPCC was set up and followed by the adoption of the United Nations Framework Convention on Climate Change (UNFCCC).

Presently the primary international policy framework against global warming and climate change is the UNFCCC, specifically the Kyoto Protocol, which sets emission limits for many of the world's most economically developed nations. Under the Kyoto Protocol, the participating developed countries are committed to reduce their GHG emissions on an average of about $5 \%$ by the target years of 2008 to 2012 (UN, 1998).

For post-Kyoto Protocol, during the United Nations Climate Change Conference 2007 held in Bali, Indonesia, it was decided to adopt the Bali Roadmap, which charts the course for a new negotiating process to be concluded by 2009 that will ultimately lead to a post-2012 international agreement on climate change (UNFCCC, 2007).

Also, during the G8 Summit 2007 held in Heiligendamm on 6-8 June 2007 , the participating countries have agreed to consider seriously the target of halving of GHG emissions by 2050 (G8, 2007). Presently, the common global target is to cut the $\mathrm{GHG}$ emissions, particularly $\mathrm{CO}_{2}$ emissions, by $50 \%$ of the present level by year 2050 . In this respect, Japan has launched the national campaign of 'Cool Earth 50', which targeting to cut the $\mathrm{CO}_{2}$ emissions up to half of the present level, by the year 2050. Also, the State of California of the United States is aiming to cut the emission to $80 \%$ below 1990 level, while London has set the target of $60 \%$ carbon emission reduction from 2000 level, both with the common target year of 2050 (TMG, 2006).

Presently the international policy frameworks on combating climate change are focusing on the developed countries. However, due to rapid increase of GHG emissions from developing countries (cf. Table 1 and Table 2), particularly for the case of China and India, there are increasing concerns on the necessity to cap emissions from the developing countries. For the case of Malaysia, Malaysia is one of the 172 countries 
signed the Kyoto Protocol but is not within the 35 countries that have committed to cap their emissions.

In spite of the absence of international commitment on the cap of $\mathrm{CO}_{2}$ emissions, Malaysian Government has been continuously promoting energy efficiency, usage of renewable energy and combating climate change. In this respect, Malaysia is one of the 16 countries signed the Cebu Declaration on East Asian Energy Security Cebu, Philippines, 15 January 2007 (ASEAN, 2007). Under the Cebu Declaration, the participating countries officially acknowledged the energy and climate change issues. All the countries concerned have agreed to make concerted efforts to improve energy efficiency, to promote alternative and renewable energy, and to mitigate GHG emissions.

\section{ROLES OF URBAN PLANNING IN HANDLING ENERGY AND CARBON DIOXIDE ISSUES}

\section{Urbanization, Energy Consumptions and $\mathrm{CO}_{2}$ Emissions}

The most significant increase of energy consumptions and GHG emissions is taking place in cities, where rapidly expanding populations enjoy higher living standards and material affluence than people in the rural areas (Fong et al,, 2007a; IGES, 2004). With respect to GHG emissions, Larson (2007) reported that the share of GHG emissions in building sector, thus in urban area, is in the range $20 \%$ to $25 \%$, and this would be higher in developed countries. It is therefore clear that strategies for the reduction of energy consumption and GHG emissions would have to be focusing on urban sector, which is the main source of energy consumptions and GHG emissions.

Rapid urbanization is in progress all over the world, and the urban population is expected to continue to increase. In 2000, world urban population was about 2.9 billion (47.2\% of world population) and it is expected to rise to about 5 billion ( $60.2 \%$ of world population) by 2030 (cf. Figure 3). During the period of $2000-2030$, the world urban population is projected to grow at an average rate of $1.9 \%$ per year. 


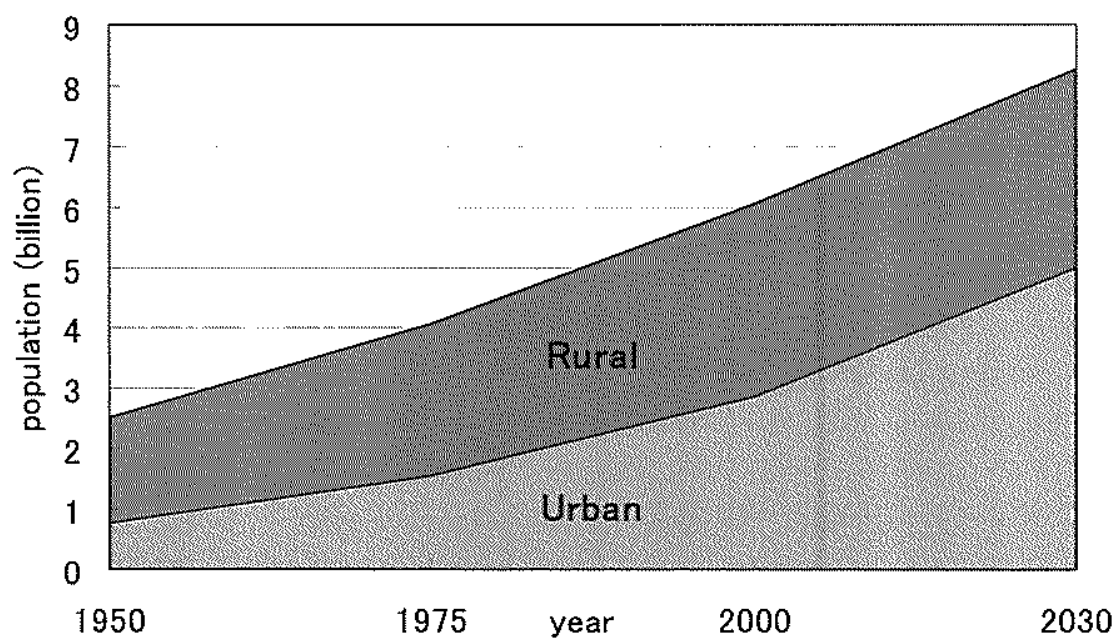

Figure 3: World urban and rural population, $1950-2030$ (UN, 2002)

Although concentration of people in cities brings advantages in terms of work and modern conveniences, it causes deterioration of living standards by various environmental problems, and in global environmental problems that spread beyond national borders (AIJ, 2005). Thus, urban environmental problems are significant elements in global environmental problems. Hence, if no immediate action is taken in cutting down the energy consumptions in urban sector, the impacts on climate change and other associated adverse impacts on the global, regional and local environments would be worsen.

Rapid urbanization has resulted in more rapid change of microclimate in the urban areas. One of the phenomena is the UHI effect whereby a zone of higher air temperature is found in the central area of a city, displaying temperature contours like an island of heat. The world average temperature increase due to UHI effect is $0.006^{\circ} \mathrm{C}$ (IPCC, 2007). There are many factors contributing to the occurrence of UHI phenomenon, and energy consumptions and $\mathrm{CO}_{2}$ emissions are among of the main factors, whereby the heat generated by the consumption of energy by air-conditioning equipment, lighting systems, automobiles, factories, etc. is released into the atmosphere (AIJ, 2005).

Although urban energy consumption is one of the main causes of UHI phenomenon as well as global climate change, unfortunately, presently, the nature of energy use in and GHG emissions from cities is still not well understood. Although a number of research projects on sectoral energy use for 
Wee Kean Fong, Hiroshi Malsumoto, Chin Siong Ho, and Yu Fat Lum

Energy Consumption and Carbon Dioxide Emission Cousiderations in the Urban Planning Process in Malaysia

industries, urban transportation and so on have been conducted from the viewpoint of managing air pollution, an overall picture of energy consumption and $\mathrm{CO}_{2}$ emissions is still missing (IGES, 2004). Due to the growing concern about $\mathrm{GHG}$, it is thus vital to understand energy use at city level in greater detail and to take GHG emissions into consideration so that systematic actions can be implemented in the urban planning process. In this respect, the present authors have carried out several studies focusing on the topics of energy conservation and $\mathrm{CO}_{2}$ reduction (Fong et al., 2007a 2007g; Ho 2005 \& 2007; Ho and Fong, 2007).

\section{Urban Planning, Energy Consumptions and $\mathrm{CO}_{2}$ Emissions}

The issues of global climate change and the UHI phenomenon has drawn concern among policy makers, urban planners and scientists on the importance of promoting a low carbon city. Researchers and policy makers responsible for climate change and energy modeling have used the term low carbon society in 2003 when the developed nations announced a target for reducing $\mathrm{CO}_{2}$ emissions in order to stabilize the world climate. Low carbon society projects have been initiated by Japan/UK collaboration to draw out comprehensive vision and definition of low carbon society (NIES, 2006).

Scientific research has been carried out to investigate the urban $\mathrm{CO}_{2}$ emission scenarios, and to study the methodologies to reduce urban energy consumptions and for achieving low carbon city. From these studies, it is obvious that urban planning is playing an important role in creating a low energy consumption and low $\mathrm{CO}_{2}$ emission city. It is found that there are several urban planning related factors that can determine the extent and nature of energy use and $\mathrm{CO}_{2}$ emissions in cities, as explained below (Fong et al. 2007a 2007g; Ho 2005 \& 2007; Ho and Fong, 2007; IGES, 2004):

\section{Compactness and density of development}

The compactness and density of urban development has very significant influence on the transportation system, thus influencing the energy consumption and $\mathrm{CO}_{2}$ emissions. A highly compact city facilitates the transit oriented development (TOD) that directly reduces the private vehicle trip and reduces the energy consumptions and $\mathrm{CO}_{2}$ emissions from the transportation sector. The compactness of urban development also influences the district heating and cooling using co-generation systems. In this respect, urban sprawl results in the necessity of lengthy distribution systems, and thus undermines efficient energy use. 


\section{Urban structure}

Urban structure and urban functions affect energy use, and thus $\mathrm{CO}_{2}$ emissions, as they influence the transportation systems. Mixed land use (residential, commercial, industrial, etc.) results in different energy use than does segregated land use. A reduction of physical separation of activities has been urged in nearly all studies of energy and spatial structure. Urban zoning policies and industrial relocation from city centers to suburb areas significantly influence the travel demand and energy use. Spatial strategies such as compact cities and TOD are effective in reducing energy demand for transportation. However, any saving from transportation energy requirement must not be overweighed by losses in economies of scale including energy economic of scale.

\section{Settlement pattern}

Comparative analyses of different urban structures suggest that an energy efficient settlement pattern would consist of small to medium sized settlements or settlement clusters. Within settlements, over-concentration should be avoided. Residential areas should be planned around more disperse clusters of employment and services in relatively compact urban sub-units. However, high densities would not necessarily be a feature of this settlement pattern.

\section{Transportation system}

The transportation system is one of the key factors affecting the urban energy consumption and $\mathrm{CO}_{2}$ emissions. As mentioned above, the transportation system is heavily depends on the urban structure. Ho and Fong (2007) pointed out that increased density favored public transportation because of critical mass. By doing so, a shift to public transportation can be done easily. Also, energy implications of transportation systems depend on a number of factors, such as the availability of infrastructure for rail and road networks, mass transportation systems, the share of public and private transportations, as well as the role of alternative fuel vehicles. Besides, socio-economic factors, such as income, are also influencing the transportation pattern. In most of the developing countries, rising incomes and perception of social status through car ownership have resulted in cars dominated transportation. This trend results in increased demand for transportation and eventually increases the urban energy demand and $\mathrm{CO}_{2}$ emissions.

\section{Income level and lifestyle}

Past research on the relationship between income and energy use at the national scale has clearly demonstrated that there is a strong correlation between per capita commercial energy consumption and GDP (IGES, 2004). It is generally accepted that per capita energy use increases with income. High income is 
associated with better lifestyles and higher material affluence, which eventually result in increased energy use and $\mathrm{CO}_{2}$ emissions.

\section{Building technologies and floor space use}

Building-related technologies such as air conditioners, district heating and cooling systems, insulation systems and other building energy management systems have a significant effect on energy use. Services such as lighting and space heating/cooling depend directly on floor space, whose use depends on a number of factors such as real estate market prices, business culture and sociocultural factors.

\section{ENERGY AND CARBON DIOXIDE EMISSION CONSIDERATIONS IN THE URBAN PLANNING PROCESS IN MALAYSIA}

\section{Spatial Planning Framework in Malaysia}

In Malaysia, development planning is practiced at three tiers of government as shown in Figure 4. At the national level, development planning in the country operates within the stated goals outlined in long-term Vision 2020 and the Outline Perspective Plans (OPPs), then followed by the short- and mediumterms Malaysia Plans, National Physical Plan (NPP) as well as the other sectoral policies/plans.

In this respect, spatial development is mainly guided by the NPP. In order to achieve the goals of NPP, which is to establish an efficient, equitable and sustainable national spatial framework to guide the country towards achieving developed nation status by 2020 , four mutually supportive objectives have been identified as follows:

a. To rationalize national spatial planning for economic efficiency and global competitiveness

b. To optimize utilization of land and natural resources for sustainable development

c. To promote balance regional development for national unity

d. To secure spatial and environmental quality and diversity for a high quality of life.

In 2006, National Urbanization Policy (NUP) was formulated to complement the NPP. NUP serves as the main thrust for all urban planning and development activities in Peninsular Malaysia including development plans at the state and local level. This policy outlines the thrusts, policies, measures and 
implementation plans to coordinate and manage the urbanization process of the country. It guides and coordinates the planning and urban development of the country to be more efficient and systematic, particularly to handle the rapid increase of urban population, with emphasis on balancing the social, economic and physical development within urban areas. It also serves as the foundation to encourage racial integration and solidarity for those who reside in the urban areas.

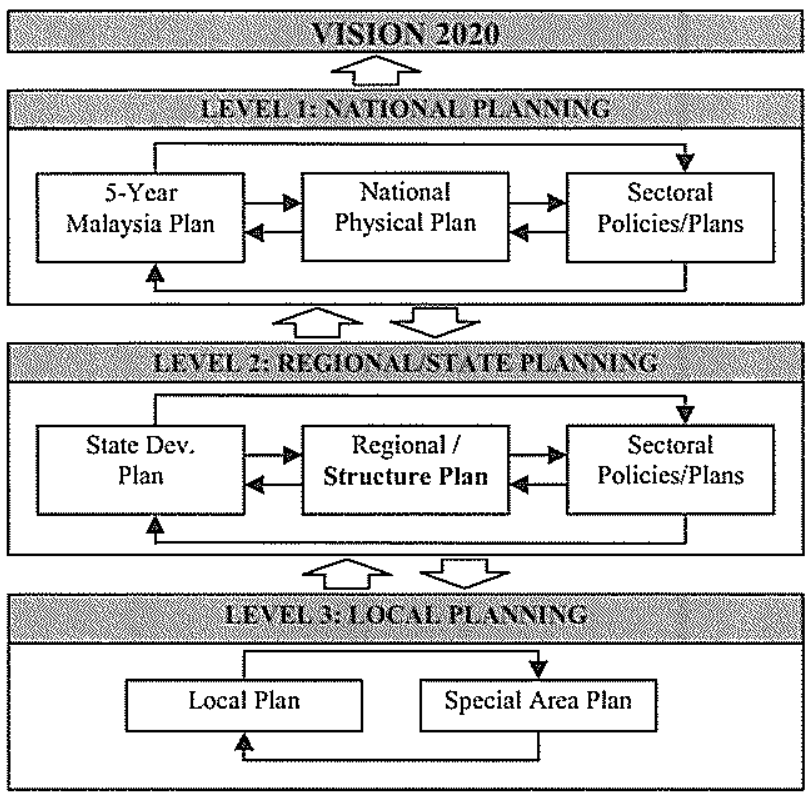

Figure 4: National development planning framework of Malaysia (JPBD, 2005)

At the state level, development is guided by the Structure Plans and sectoral policies that are articulated from time to time. Local level planning is carried out in the form of statutory development plans such as the Local Plans and Special Area Plans for the local authority areas. Structure Plans distribute the expectation of development within each state and propose major economic and infrastructure projects for the states. The time perspective for structure plans is 20 years, and for the current set of Structure Plans, commensurate with the time perspective of Vision 2020. (JPBD, 2005) 


\section{Absence of Energy Consumption and $\mathrm{CO}_{2}$ Emission Considerations}

Presently, most of the developed countries are committed to cut down their $\mathrm{CO}_{2}$ emissions as stipulated under Kyoto Protocol as well as the recent declaration during the G8 Summit 2007 in Heiligendamm, Germany (G8, 2007). In this respect, developing countries are still lapsed behind most of the developed countries. However, being a country of responsible, Malaysia, one of the fastest growing developing countries in Southeast Asia, is continuously putting aggressive efforts in combating global warming. This section examines the present efforts in controlling energy consumptions and $\mathrm{CO}_{2}$ emissions in Malaysia, from the perspective of spatial planning.

As mentioned above, spatial development in Malaysia is mainly guided by the NPP. Presently, there is no specific policy related to energy conservation and controlling of $\mathrm{CO}_{2}$ emissions in the NPP. However, there are several principles that have indirect implications on energy conservation, namely Policy 3: Maximize use of existing infrastructure, Policy 6: Favor public transport over private transport, and Policy 7: Compact urban forms.

For the case of NUP, although NUP is a comprehensive plan, there is also no policy directly referred to energy conservation and reduction of $\mathrm{CO}_{2}$ emission. Policies that may have indirect implications on energy planning are found in Policy Thrust 1 and Policy Thrust 3 as follows:

\section{Thrust 1 : Towards an efficient and sustainable urbanization}

Thrust 2 : Development of a resilient, dynamic and competitive urban economy

Thrust 3 : Towards an integrated and efficient urban transportation system

Thrust 4 : Provide quality urban services, infrastructure and utility

Thrust 5 : Create a conducive urban living environment with a distinct identity

Thrust 6 : Effective urban governance

Part of Policy Thrust 1 - Towards an Efficient and Sustainable Urbanization highlighted the policy to promote national growth conurbation policy, and specific conurbation zones have been identified. The advantage of the national conurbation policy in term of energy conservation is that it promotes economic of scale and energy efficient system of these designated growth regions. 
Compact city development can be developed to optimize energy utilization in the region by reduction in movement and transportation energy.

\begin{abstract}
Policy Thrust 3 - Towards an Integrated and Efficient Urban Transportation System promotes an integrated and efficient urban transportation system. As transportation sectors consume more than a quarter of the total energy consumption in Malaysia, an efficient and comprehensive transportation system is vital. The current pressing issues are increase in private car ownership and low utilization of public transportation. The policy thrust promotes the use of integrated public transportation system emphasizing on multi-modal transportation terminal, implementation of TOD development, provision of Park and Ride Terminals, use of environmental-friendly vehicles to reduce level of air pollution.
\end{abstract}

\title{
SECTORS OF STUDY:
}

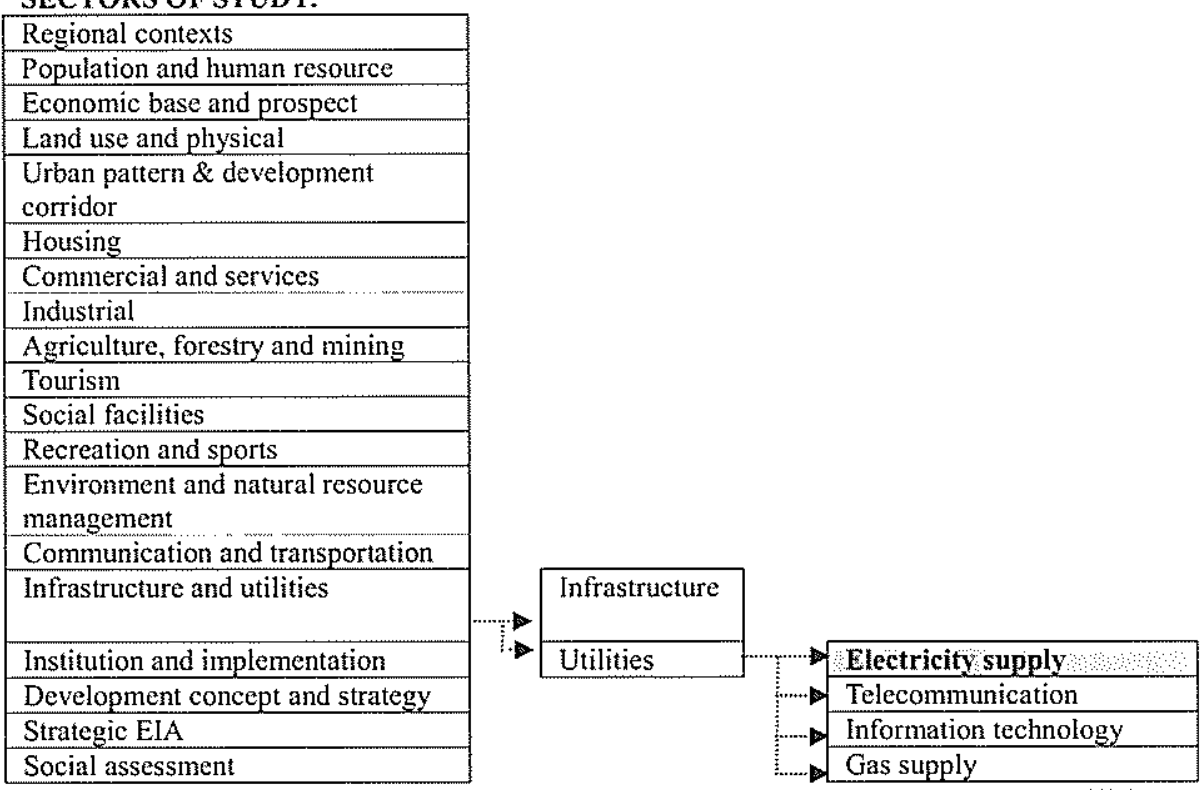

Figure 5: Energy sector (electricity supply) was a sub-sector under the utilities sector in the Johor Structure Plan 2001-2020 study (JPBD, 2001)

For the State and local levels, in the process of the preparation of Structure Plans and Local Plans, energy sector study very often focuses on fulfilling the energy demand rather than investigating measures to reduce the city-wide or region-wide energy consumption through an integrated approach. For example, in the study of Johor Structure Plan 2001-2020, the energy sector was 
considered as one of the sub-sectors under the utility sector, also, in fact, the study focused on electricity supply rather than energy demand and supply as a whole (cf. Figure 5). Besides, energy issue was also not covered in the environmental sector despite that energy and $\mathrm{CO}_{2}$ emission issues have been widely recognized as global environmental issues that require immediate attentions from all parties.

On a whole, spatial planning framework in Malaysia is still lacking serious considerations on the issues of energy consumptions and $\mathrm{CO}_{2}$ emissions. Although there are some policies in the NPP and NUP indirectly favoring energy conservation, there is still no measure that directly focuses on promoting energy conservation/efficiency and capping $\mathrm{CO}_{2}$ emission. Also, instead of promoting energy conservation/efficiency, most of the Structure Plans, focus on fulfilling the continuously increasing energy demand so as to support the desired high economic growth rate.

\section{CONCLUSIONS REMARKS}

This paper highlighted the importance of energy conservation and reduction of $\mathrm{CO}_{2}$ emissions from both global and Malaysian points of view. Although Malaysia is presently not a developed nation, and there is no clear commitment to cut down $\mathrm{CO}_{2}$ emissions under any international framework, toward achieving the developed nation status under the Vision 2020 , it is necessary to take concerted efforts to cap $\mathrm{CO}_{2}$ emissions as part of the global efforts in combating global warming and climate change, while maintaining the desired economic and population growths.

The earlier parts of this paper pointed out that the main contributors to the global warming phenomenon are energy use and land use change. In this respect, urbanization is one of the essential aspects that must not be neglected in handling global warming issues, as the main portion of energy consumption and $\mathrm{CO}_{2}$ emission is occurring in the cities. Hence, spatial planning that deals with planning for land use and urban structure plays a very important role in controlling energy consumption and $\mathrm{CO}_{2}$ emissions in the urban systems.

While many countries have recognized the importance of the role of spatial planning in energy conservation and reduction of $\mathrm{CO}_{2}$ emissions, in Malaysia, to date there is still no spatial planning policy that directly deals with the energy and $\mathrm{CO}_{2}$ issues. Instead, in the urban planning process, efforts have been put on fulfilling the high energy demand (which focusing more on electricity supply) so as to support the desired high economic growth. Hence, this paper aims to 
highlight the importance of energy conservation and $\mathrm{CO}_{2}$ reduction as the core considerations in the spatial planning process in Malaysia, from national till local levels.

For instance, in the preparation of Structure Plans, instead of trying to fulfill the expected high energy demand, measures should be taken to cut down the energy consumptions and $\mathrm{CO}_{2}$ emissions, so as to achieve a balance between economic development and environmental conservation. Every proposal in the structure plan, to a certain extent, would have some impacts on the energy consumptions and $\mathrm{CO}_{2}$ emissions in the planning area as a whole. For instance, a proposal to convert a forest area to commercial development would not only increase the energy consumption and $\mathrm{CO}_{2}$ emission in the area concerned, but will also reduce the capacity of carbon sink due to the loss of green areas. Hence, due consideration must be taken on the impacts of each proposal on energy consumptions and $\mathrm{CO}_{2}$ emissions. In this respect, it is necessary to develop and incorporate a decision making tool to assess the overall impact of development plans (or proposal options) on the city or regional level energy consumptions and $\mathrm{CO}_{2}$ emissions as a whole. This decision making tool should be able to assist the decision makers as well as the other relevant stakeholders in making the best choices of development options with due considerations on both economic and environmental aspects.

For the development of this decision making tool, it is necessary to develop a comprehensive model that is able to provide a holistic analysis on the various development options on the overall urban energy consumptions and $\mathrm{CO}_{2}$ emissions. In this respect, the present authors are attempting to develop a comprehensive but reasonably simple model that is suitable to be applied in the urban planning process in Malaysia, and parts of the research outputs are reported in Fong et al. (2007a \& 2007b) and Ho and Fong (2007).

There are many strategies that can conserve energy and reduce $\mathrm{CO}_{2}$ emissions through spatial planning. For the case of Malaysia, being a developing country, economic development is no doubt the most important consideration in any development plan. Hence, it is vital to identify the best practice with minimum energy consumption and $\mathrm{CO}_{2}$ emission while achieving the desire economic growth. In this respect, the concept of the Kaya Identity would serve as an important guide in achieve a low energy consumption and low $\mathrm{CO}_{2}$ emissions society under the concept of low carbon city. The Kaya Identity involved 3 main concepts, namely per capita activity, energy intensity and carbon intensity (cf. Figure 6). From the concept, it is clear that reducing $\mathrm{CO}_{2}$ emission by reducing per capita activity is not feasible for a developing country like Malaysia. 
Instead, it is important to reduce $\mathrm{CO}_{2}$ emission by reducing energy intensity and carbon intensity.

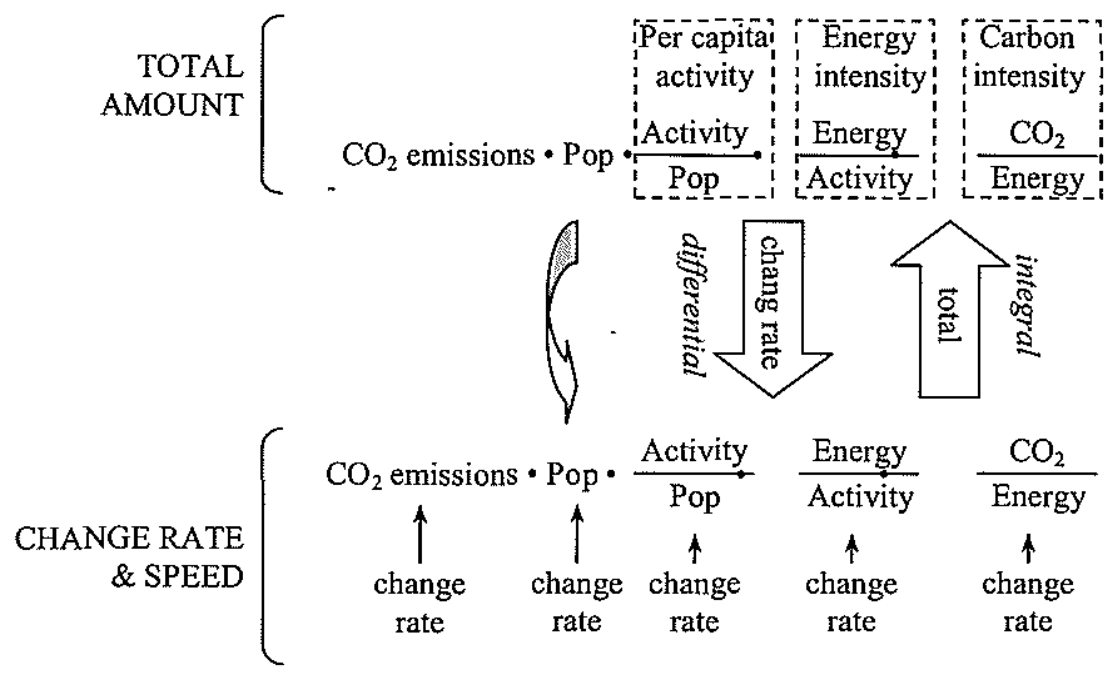

Figure 6: Concept of Kaya Identity

(Source: NIES, 2006)

In order to examine the relationship between energy and spatial planning, it is necessary to look into more detailed variables of both of these aspects. The three main components in Figure 7 define the interrelationship between energy demand and spatial structure are (1) Energy demand and supply, (2) Urban form and other aspects of built environment, and (3) Mechanisms of interaction between the energy system and spatial structure. Demand and supply of energy will influence the urban form. The configuration of urban form will affect the interaction of spatial structure and system interaction. It will then form a cyclic cycle in the near future when its technology is more advance and appropriate as well as the demand for clean energy is more pressing in future.

This simplified concept attempts to illustrate the energy-spatial relationship, which in reality is far more complicated. The concept must also allow feedback systems that would themselves stimulate new developments and adjustments in the energy system. From the concept, the most commonly explored interactions have been those between various attributes of urban form (size, shape and density) and energy requirement for transportation. The questions that arise are whether any anticipated society changes should be guided by planning intervention into socially desirable forms or whether land use planning control 
is used to ensure spatial structures, which are both efficient in their consumption of energy resources and realistic.

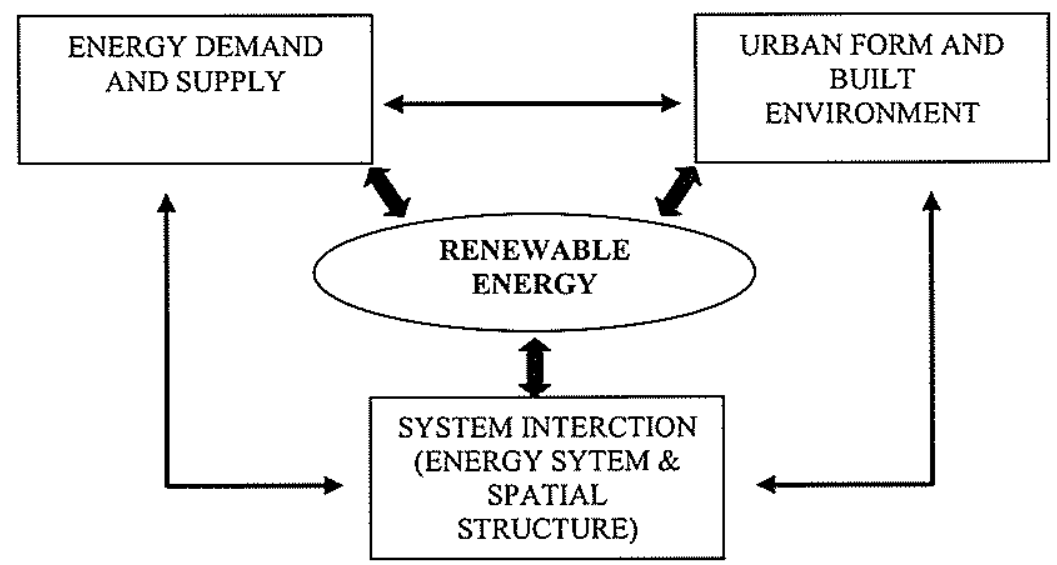

Figure 7: Interrelationship between energy and urban form (Ho, 2007)

On the whole, while it is widely recognized that in achieving a low energy consumption and low $\mathrm{CO}_{2}$ emission sustainable society, it is important to carry out continuous research on the energy saving technologies and measures in various energy consuming sectors such as transportation, industrial, commercial and residential sectors; more importantly, it requires a holistic analysis and clear understanding of the nature of the highest energy consuming and $\mathrm{CO}_{2}$ emission sector i.e. the urban sector as a whole. This paper thus serves a the starting point towards incorporating energy and $\mathrm{CO}_{2}$ issues as the core part of spatial planning process in Malaysia, in achieving a low carbon sustainable society of future.

\section{REFERENCES:}

AIJ. 2005. Architecture for a Sustainable Future - All about the Holistic Approach in Japan. Tokyo: IBEC.

Anqing Shi. 2001. Population Growth and Global Carbon Dioxide Emissions. IUSSP General Conference, 18-24 August 2001, Salvador, Brazil. SessionS09. (http://www.iussp.org/Brazil2001/ soo/S09_Shi.pdf, Retrieved: 4 Nov 2007)

ASEAN. 2007. Cebu Declaration on East Asian Energy Security Cebu, Philippines, 15 January 2007. Jakarta: The Association of Southeast Asian Nations. (http://www.aseansec.org/19319.htm. Retrieved: November 2007) 
Azman Zainal Abidin, Siti Indati Mustapa, Radin Diana Radinahmad and Komathi Mariyappan. 2006. Development of the greenhouse gas (GHG) inventory for the energy sector in Malaysia. Greenhouse Gas Inventory Development in Asia - Esperience from workshops on greenhouse gas inventories in Asia, 48-53.

EIA. 2005. International Energy Annual 2005. Washington DC: Energy Information Administration. (http://www.eia.doe.gov/iea/wecbtu.html, Retrieved: October 2007)

EIA. 2007. International Energy Outlook 2007. Washington D.C.: Energy Information Administration, Department of Energy.

EPU. 2001. The Third Outline Perspective Plan 2001-2010. Putrajaya: The Economic Planning Unit.

EPU. 2006. Ninth Malaysia Plan 2006-2010. Putrajaya: The Economic Planning Unit.

EPU. 2007. Malaysia Economy in Figures. Putrajaya: The Economic Planning Unit. (www.epu.jpm.my, Retrieved: 8 November 2007)

Fong, W.K. 2007. A Study on Future Urban Energy Consumption Trend and the Interrelationships between Lifestyle and Residential Energy Consumption. Unpublished Master Thesis. Toyohashi, Japan: Toyohashi University of Technology.

Fong, W.K., Matsumoto, H., Lun Y.F. and Kimura, R. 2007c. Energy Saving Potential of Summer Time on Household Lighting in Different Regions of Japan. Proceedings of International Conference on Sustainable Building Asia (SB07 Seoul), Vol.1, pp. 203-208, 27-29 June 2007, Seoul, Korea.

Fong, W.K., Matsumoto, H., Lun Y.F. and Kimura, R. 2007d. Household Energy Consumption under Different Lifestyles. Proceedings CD-ROM of the 9th REHVA World Congress Clima 2007 WellBeing Indoors (Clima 2007 WellBeing Indoors) (CD1 Proceeding B04E1151), 10-14 June 2007, Helsinki, Finland.

Fong, W.K., Matsumoto, H., Lun, Y.F. and Kimura, R. 2007a. System Dynamic Model for the Prediction of Urban Energy Consumption Trends.

Proceeding I of the 6th International Conference on Indoor Air Quality, Ventilation \& Energy Conservation in Buildings (IAQVEC 2007), 28-31 October 2007, Sendai, Sendai, Japan. 762-769.

Fong, W.K., Matsumoto, H., Lun, Y.F. and Kimura, R. 2007b. System Dynamic Model as Decision Making Tool in Urban Planning from the Perspective of Urban Energy Consumption. Seminar Proceedings of the 3rd Seminar of JSPS-VCC (Group VII), 10-11 September 2007, Johor Bahru, Malaysia. 99110

Fong, W.K., Matsumoto, H., Lun, Y.F. and Kimura, R. 2007e. Energy Savings Potential of the Summer Time Concept in Different Regions of Japan from 
the Perspective of Household Lighting. Journal of Asian Architecture and Building Engineering, 6(2), pp.371-378.

Fong, W.K., Matsumoto, H., Lun, Y.F. and Kimura, R. 2007f. Impacts of Household Pattern, Geographical Location and Climate on Household Energy Consumption in Japan, and the Energy Saving Potential of Summer Time Concept. Summaries of Technical Papers of Annual Meeting, Architectural Institute of Japan, Vol. D-2, pp.497-498, 29-31 August 2007, Fukuoka, Japan.

Fong, W.K., Matsumoto, H., Lun, Y.F. and Kimura, R. 2007g. Influences of Indirect Lifestyle Aspects and Climate on Household Energy Consumption. Journal of Asian Architecture and Building Engineering, 6(2), 395-402.

G8. 2007. Chair's Summary. Heiligendamm: G8 Summit 2007 Heiligendamm. (http://www.g-8.de/Webs/G8/EN/G8Summit/Summit Documents/summitdocuments.html, Retrieved: November 2007)

Ho, C.S. 2005. Local Authorities Planning for Sustainability - Towards Implementing Energy Consumption Policies in Development Plan. Seminar Proceedings of the 2nd Seminar of JSPS-VCC (Group VII), 22-23 September 2005, Shiga, Japan. 55-67.

Ho, C.S. 2007. Towards a Sustainable Society From the Perspective of Energy Conservation and Urban Structure. Seminar Proceedings of the 3rd Seminar of JSPS-VCC (Group VII), 10-11 September 2007, Johor Bahru, Malaysia. 71-87.

Ho, C.S. and Fong, W.K. 2007. Planning for Low Carbon Cities: The case of Iskandar Development Region, Malaysia. Seminar Towards establishing sustainable planning and governance II, Sungkungkwang University Seoul on Nov 29-30, 2007...

IEA. 2007. Key World Energy Statistics 2007. Paris: International Energy Agency.

IGES. 2004. Urban Energy Use and Greenhouse Gas Emission in Asian Mega Cities: Policies for a Sustainable Future. Kanagawa: Institute of Global Environmental Strategies.

IPCC. 2001. Climate Change 2001: The Scientific Basis. Geneva: Intergovernmental Panel on Climate Change.

IPCC. 2004. 16 Years of Scientific Assessment In Support of the Climate Convention. Geneva: Intergovernmental Panel on Climate Change.

IPCC. 2005. IPCC Special Report on Carbon Dioxide Capture and Storage Climate Change 2007. Geneva: Working Group III of the Intergovernmental Panel on Climate Change.

IPCC. 2007. Climate Change 2007: The Physical Science Basis. Geneva: Intergovernmental Panel on Climate Change. 
Wee Kean Fong, Hiroshi Matstumoto, Chin Siong Ho, and Yu Fat Lun

Energy Consumption and Carbon Dioxide Emission Considerations in the Urban Planning Process in Malaysia

JPBD, 2001. Johor Structure Plan 2001-2020 - Technical Report (Rancangan Struktur Negeri Johor 2001-2020 - Laporan Pemeriksaan). Johor Bahru: Department of Town and Country Planning.

JPBD. 2005. National Physical Plan. Kuala Lumpur: Department of Town and Country Planning, Peninsular Malaysia.

Larson, N. 2007. Sustainability Issues for the 21st Century Construction Industry. Proceedings of International Conference on Sustainable Building Asia, Vol.I, 27-29 June 2007, Seoul, Korea. 23-30.

MOSTE. 2000. Malaysia Initial National Communication. Kuala Lumpur: Ministry of Science, Technology and the Environment, Malaysia.

NIES. 2006. Aligning Climate Change and Sustainability-Scenarios, Modeling and Policy Analysis. Tsukuba: AIM Integrated Model Centre for Global Environmental Research, National Institute for Environmental Studies.

TMG. 2006. Tokyo Environmental White Paper 2006. Tokyo: Tokyo Department of Environment. (http://www2.kankyo.metro.tokyo.jp/kikaku/hakusho/ 2006/outline.html, Retrieved: November 2007) (in Japanese)

TMG. 2006. Tokyo Environmental White Paper 2006. Tokyo: Tokyo Department of Environment.

(http://www2.kankyo.metro.tokyo.jp/kikaku/hakusho/2006/outline.html, Retrieved: November 2007) (in Japanese)

UN. 1998. Kyoto Protocol to the United Nations Framework Convention on Climate Change. New York: United Nations.

UN. 2002. World Urbanization Prospects: The 2001 Revision. New York: United Nations.

UN. 2007. Sustainable Development Issues. United Nations Division for Sustainable Development. (http://www.un.org/esa/sustdev/documents/ docs sdissues.htm, Retrieved: October 2007)

UNEP. 2007. National Carbon Dioxide (CO2) Emissions Per Capita. Arendal: United Nations Environment Programme/GRID-Arendal.

(http://maps.grida.no/go/graphic/national_carbon_dioxide_co2_emissions_ per_capita. Retrieved: Nov 2007)

UNFCCC. 2007. Bali Action Plan (Decision -/CP.13). Bonn: United Nations Framework Convention on Climate Change. (http://unfccc.int/meetings/ cop_13/items/4049.php, Retrieved: December 2007)

WRI. 2007. EarthTrends Environmental Information. Washington D.C.: World

Resources Institute. (http://earthtrends.wri.org, Retrieved: Nov 2007) 


\section{SOME ISSUES ON CRIMES IN} THE MALAYSIAN'S NEWSPAPERS 


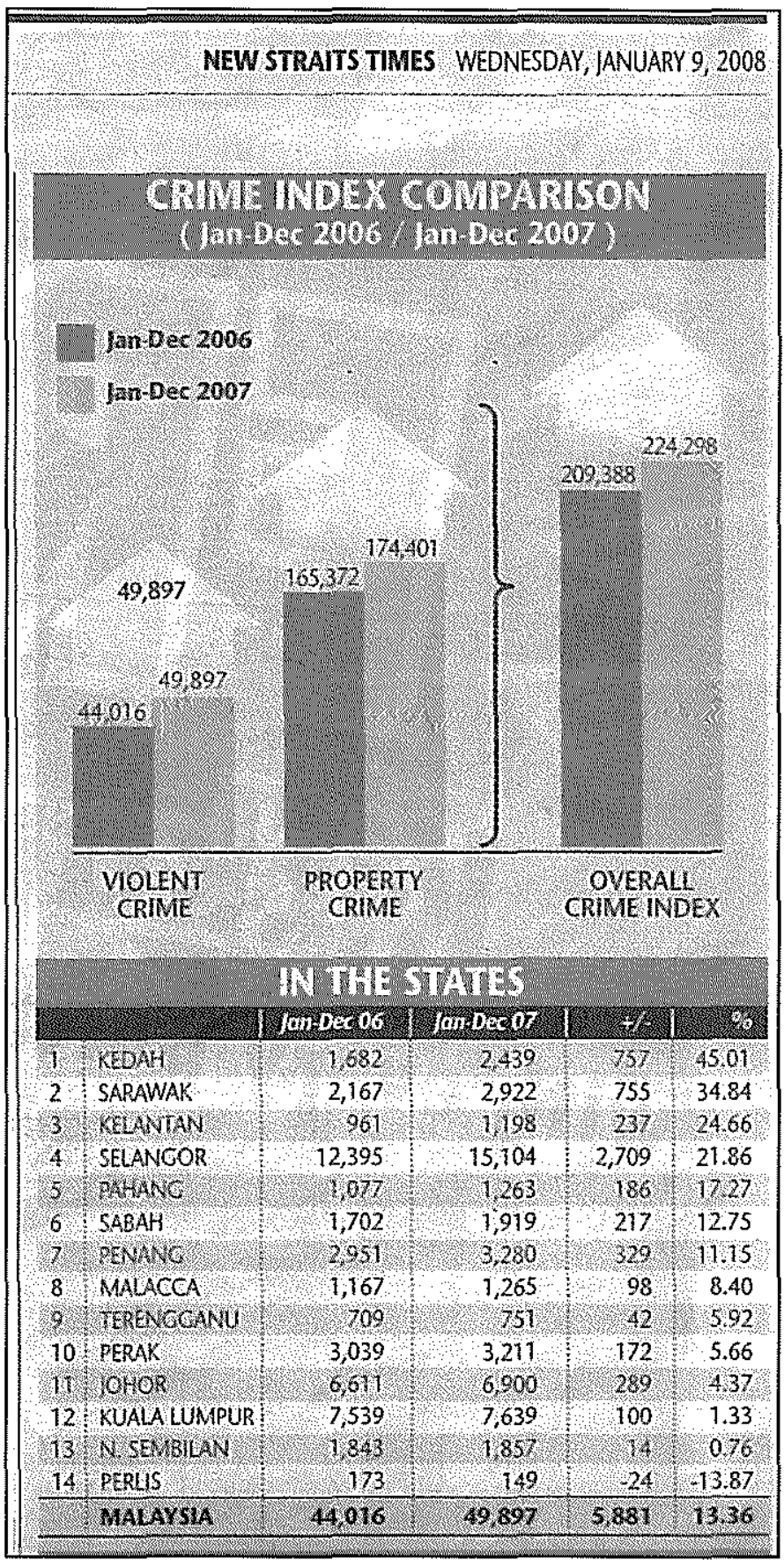




\begin{tabular}{|c|c|c|c|c|}
\hline \multicolumn{5}{|c|}{ NEW STRAITS TINES } \\
\hline \multicolumn{5}{|c|}{ 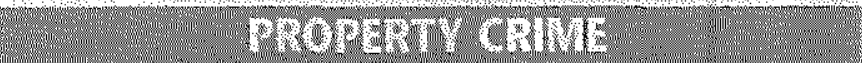 } \\
\hline 0 monct & $\ln 10 \times 6$ & 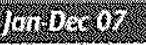 & 2 & $\cos 2$ \\
\hline Bugrary night) & 20080 & $2+4 \times 0$ & 4.360 & $2 \times 7 \times$ \\
\hline Car thefts. & 11154 & 12,427 & 1,273 & 1141 \\
\hline hrser & 42,272 & 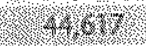 & $2,1 / 5$ & 508 \\
\hline Burglary (day) & 8,792 & 9,159 & 367 & 417 \\
\hline mororyce tretrs & 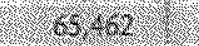 & 67,8 & 2,222 & 2,24 \\
\hline Snatch thefts & 17074 & 11,27 & 53 & 0.48 \\
\hline 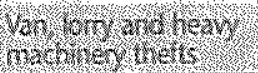 & 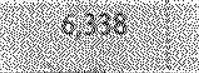 & (3) & r. & 2057 \\
\hline Torat & 165272 & $17,50 \%$ & 20,9 & 5.46 \\
\hline \multicolumn{5}{|c|}{ 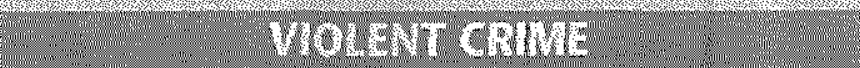 } \\
\hline orrons $=1$ & 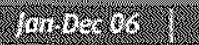 & $20 x=0 \%$ & - & rite \\
\hline 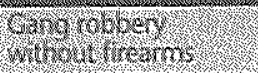 & 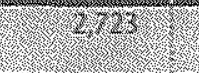 & $7.06 \%$ & $4 x^{2}+2$ & 18983 \\
\hline Rape & 2,454 & 3,177 & 723 & 29,46 \\
\hline 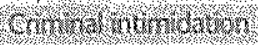 & $60 \%$ & 8,10 & 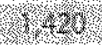 & 21,20 \\
\hline Assaules & 5,843 & 6,806 & 963 & 16,48 \\
\hline 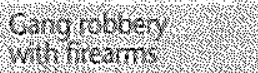 & 67 & 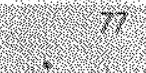 & (2) & 1.rob \\
\hline Rioting & 2291 & 2,608 & 317 & 13.84 \\
\hline Woert & 2,060 & 2320 & 256 & $12 \times 10$ \\
\hline Extortion & 3,554 & 1,692 & 138 & 8.88 \\
\hline Wurder & 606 & 588 & Vis & -2.97\% \\
\hline $\begin{array}{l}\text { Robbery without } \\
\text { firearms }\end{array}$ & $19,46 ?$ & 17,241 & 2226 & 11.6 \\
\hline pobtery. & 248 & 262 & (6) & (x) $8>5$ \\
\hline rorru & 4.016 & 49.897 & 5881 & 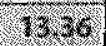 \\
\hline
\end{tabular}




\section{Rising crime index has Abdullah worried}

\section{By V. Vasudevan newsenstcom.my}

KLALA IUMPUR: The crime in. flex lias gone up worryingly and multi-pronged strateng is lycing applied to bring it down, the prime mintster soukd.

"I am worried and angnne look. ing at it will besworioni. Seriously. an wery concersed about the per. an wery corkeried about hac per: contage of crime in Malaysia, Datuk Seri

"Wip have to act on this quickly. the bate to make sure the people know shout the sturation," he ssio after a three-hour brieflng at Bukit Aman.

The number of serious crimes increased by 13,36 per cent natonwido last year, with gang nob. bety villyout the use of fircarms rasing by nore than 159 per cent. "The crime index ys geting higher and it can create anxicty among the pubtic.

"When there is fear, the public will be apprehensive aboul gaving out si nigit to the hospital or cren the sundry shop:

Abdullah sekh to belp armest and bring town the crime figures, the polico had conne up with a stratepy, including:

- hitring of contract potico parsonnel whto are retiring or haverecired; ;

- installing mara closed-ctreut telesision cameras in butldings
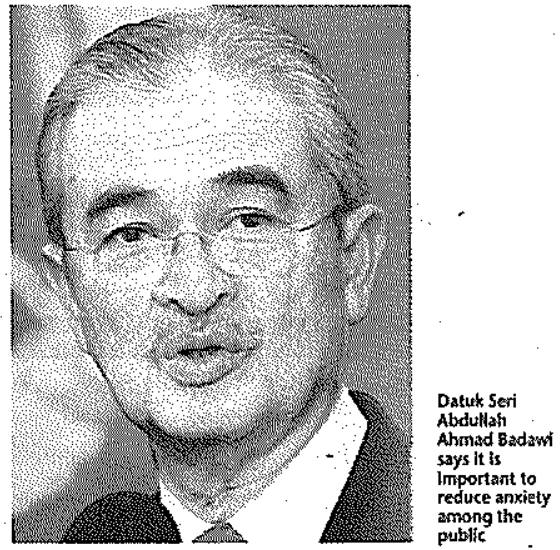

and public pieces

- setting yp moro polico stations in shophouses and housing estates;

- appointing civilians in adnir. stralivo positions and thereby re-

lessing police persunuel for their main dulies:

- fast-1racking recruituent.

Abdullah said the inessures the

government was taking would bring down the crimo rate. Iic action and reduce unvisty anosing the putbite.

Aldullah said the spike in crime statisties was partly attributed to to the crime inder sitios 2006 .

They are: criminal intimidation, outrating modesty; causing hirt extoriton and rioting (fights: int-
"It is important to take this dras the inclusion of frue nuw catergories volsing mose than live peoplo or demaging puldic property; not strect demonstrations)

Abdullat sakd the government has becn addressing the ypwar trend to crinet ard hend in tha last budget set aside furds for the recruitment of $(x), 0060$ police personnel by 2010.

-It is not an easy task. Anyone wanting to ba a policeman muts be trained and tits takes time. More. ower, we don't hase that many poover, we don't have that many
lico training centres," ho saidt.

lico training eesntres," hos sald.

The prine minister saik the govermment was satting up two new

langkaw, Kedah, and Bentong. Pahang.

He sait funding for the mestsires would not be a prolulem as there were allocalions for the po fice which lited yel to be utilised.

"These funds are for infrastrut:ture dowelopment and we can use them for this purpose first and later provide adiditional futuls for the infrastructure.

Ite snid the goxernแzant laxd been doing its best to relain the best policepersennel.

"Wo want to altract the linst and retain the less." los said, while jockedures were in place to cmsure speedy promolions withou depending on intervievs ayd re ports. Ha said periormance and exsminations wera lveint used to provido spoody promolions for proside speedy promolions po 


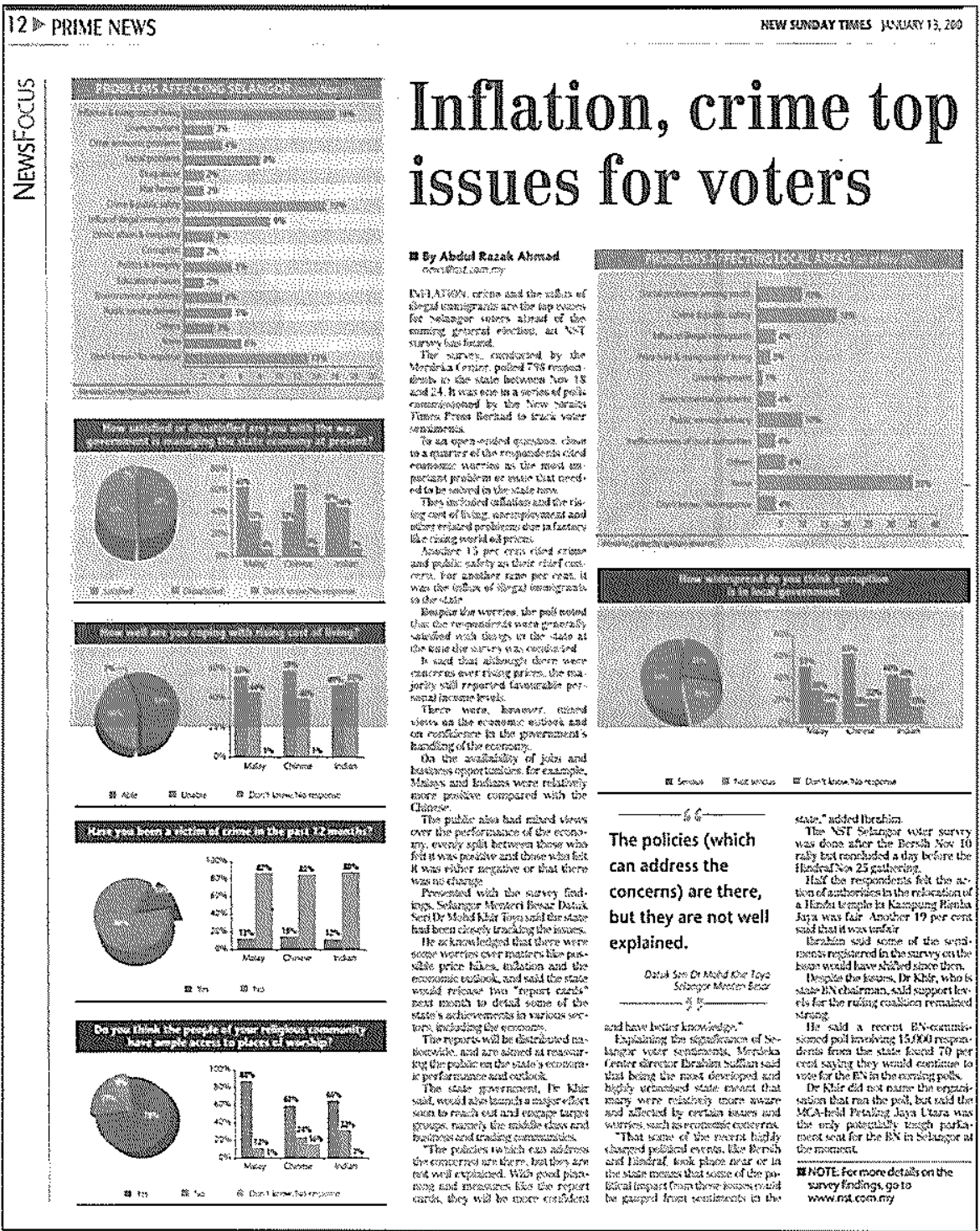




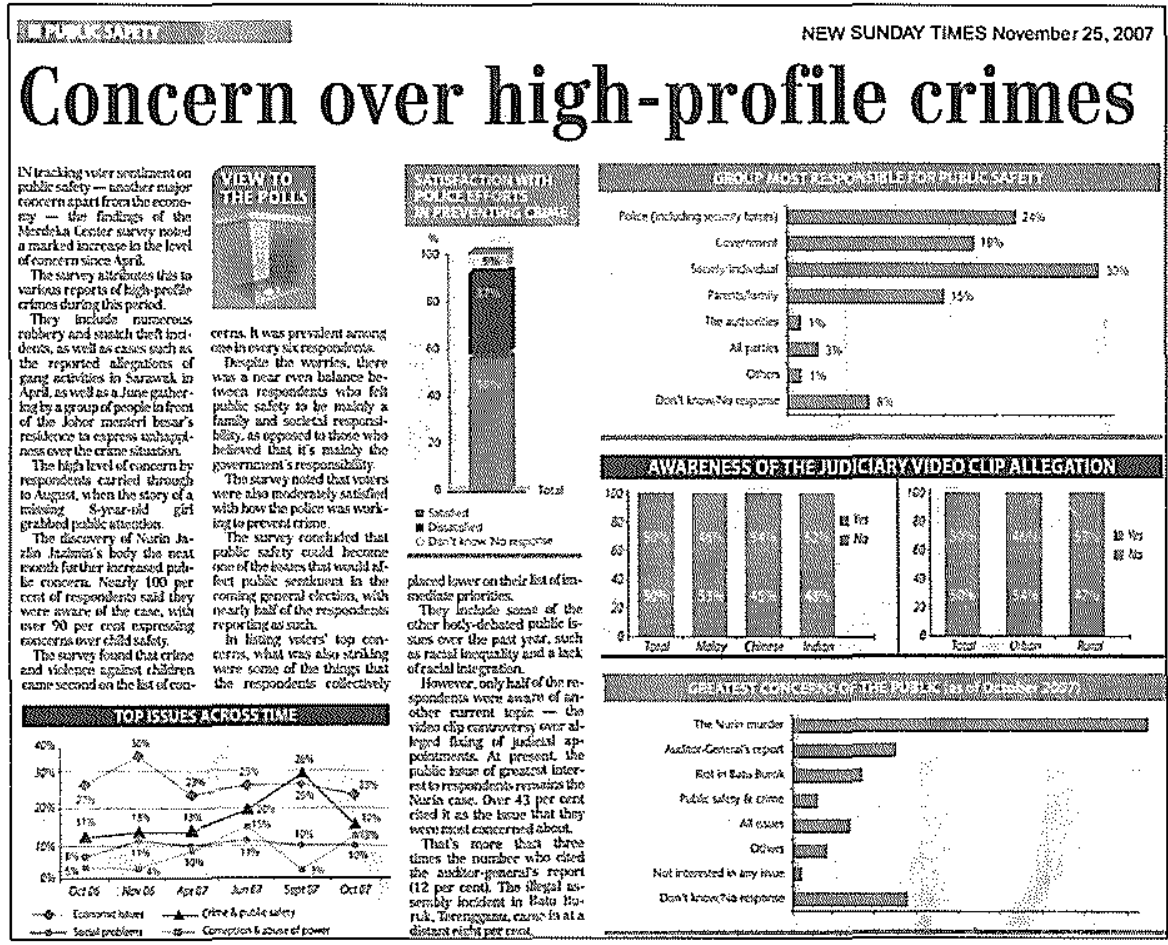

NEW SUNDAY TIMES November 25, 2007

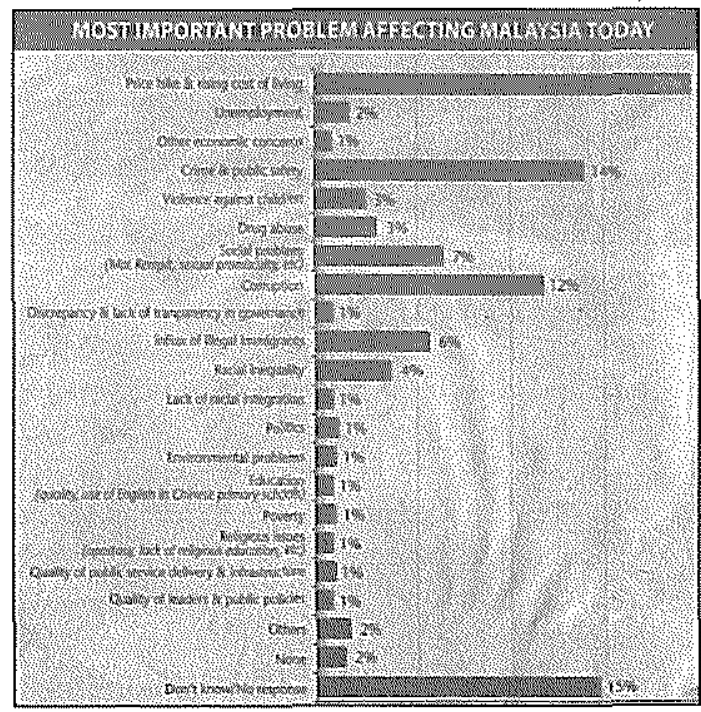

